\title{
Novel conjugated hybrid films based on a new polyoxotitanate monomer
}

Received 00th January 20xx, Accepted 00th January 20xx

DOI: $10.1039 / \times 0 \times x 00000 x$

www.rsc.org/
Gang Liu, ${ }^{a}$ Xing Yang, ${ }^{a}$ Yaokang Lv, ${ }^{a}, \mathrm{~d}^{*}$ Jun Chen, ${ }^{a}$ Wenyan Dan, ${ }^{\mathrm{b}}$ Zuofeng Chen, ${ }^{\mathrm{b}}$ Laurent Ruhlmann, ${ }^{d}$ Dominic S. Wright, ${ }^{c}$ Cheng Zhang ${ }^{a,}{ }^{*}$
Novel polyoxotitanate (POT) hexamer $\left[\mathrm{Ti}\left(\mu_{3}-\mathrm{O}\right)(\mathrm{O} \mathrm{Pr})(\mathrm{TA})\right]_{6}$ (TA= thiophene-3-acetic acid) has been employed as a nano-building block, producing a series of novel hybrid conjugated films Poly(EDOT-POT)s by electrochemical copolymerization with 3,4ethylenedioxythiophene (EDOT). One of these polymers Poly(EDOT-POT)-1 can be used as fast-ion electrode material and has improved electrochromic properties and $35 \%$ higher capacitance $(102.5 \mathrm{~F} / \mathrm{g})$ than that of bare PEDOT $(75.8 \mathrm{~F} / \mathrm{g})$ at a current density of $1 \mathrm{~A} / \mathrm{g}$.

Nanostructured titania composites have attracted considerable attention in photocatalysis and photoelectrical applications as well as energy storage due to their inherent physicochemical and unique nanoscale properties. ${ }^{1-9}$ However, uneven dispersion, agglomeration and heterogeneous interface problems in their composites often hinder the performances of these material. ${ }^{10}$

During the past decade, there has been considerable interest in polyoxotitanate (POT) cages, which possess well-defined inorganic $\mathrm{Ti}_{\mathrm{x}} \mathrm{O}_{\mathrm{y}}$ cores surrounded by organic ligands. ${ }^{11-14}$ Recently, POTs have proved to be particular effective precursors for formation of various titania composites, with controlled composition and morphology. ${ }^{15-21}$ POTs also can be employed as 'nano-blocks' for the formation of new organic-inorganic hybrid materials. ${ }^{22}$ 27 For example, the introduction of styrenic groups allows copolymerization of the POT monomers $\mathrm{Ti}_{16} \mathrm{O}_{16}(\mathrm{OEt})_{32}$ ${ }_{x}\left(\mathrm{OPhCH}=\mathrm{CH}_{2}\right)_{x}$ with styrene to form hybrid materials with three dimensional networks in which the titania nano-fillers are covalently linked to the organic polymer. ${ }^{25}$

\footnotetext{
College of Chemical Engineering and Materials Science, Zhejiang University of Technology, Hangzhou, 310014, China. E-mail: czhang@zjut.edu.cn, yaokanglv@zjut.edu.cn.

b. Department of Chemistry, Tongji University, Shanghai 200092, China.

c. Department of Chemistry, University of Cambridge, Lensfield Road, Cambridge CB2 $1 E W, U K$

d. Institut de Chimie (UMR au CNRS $n^{\circ} 7177$ ), Université de Strasbourg, 4, rue Blaise Pascal CS 90032, F-67081 Strasbourg Cedex, France.

† Electronic Supplementary Information (ESI) available: Synthesis, crystal data and analytic characterization of POT-1, CCDC 1537426; preparation and characterization of DPE-1. For ESI and crystallographic data in CIF or other electronic format see DOI: $10.1039 / \mathrm{c} 000000 \mathrm{x} /$.
}

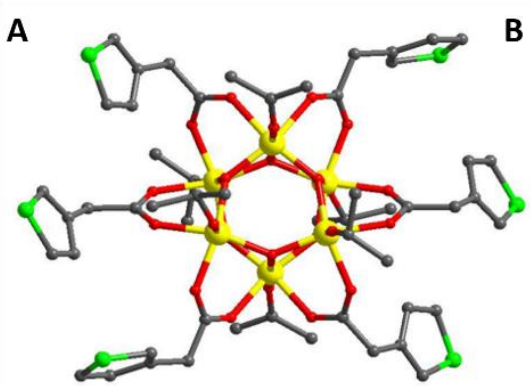

B

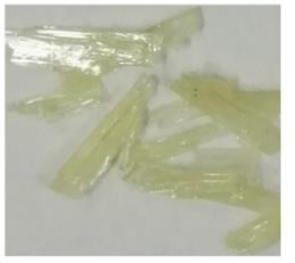

Fig. 1 (A) Solid-state structure of POT-1, H-atoms have been omitted for clarity (red $=\mathrm{O}$, gray $=\mathrm{C}$, green $=\mathrm{S}$, yellow $=\mathrm{Ti})$; $(\mathrm{B})$ Photographic image of POT-1

In the current work, we have explored the incorporation of the polymerizable ligand thiophene-3-acetic acid (TA) into POTs. The new POT cage $\left[\mathrm{Ti}\left(\mu_{3}-\mathrm{O}\right)(\mathrm{O} \text { Pr) }(\mathrm{TA})]_{6}\right.$ (POT-1; Fig. 1) functions as a monomer building block in the copolymerization with conjugated monomers such as 3,4-ethylenedioxythiophene (EDOT), thiophene or pyrrole, forming a range of hybrid conjugated materials (Scheme 1). The electrochemical performance of these novel materials was studies.

Light yellow crystals of POT-1 are obtained via the solvothermal reaction of $\mathrm{Ti}\left(\mathrm{O}^{\prime} \mathrm{Pr}\right)_{4}$ and TA in propan-2-ol (Fig. 1B and ESI ${ }^{+}$). A Single crystal X-ray diffraction (SXRD) analysis shows that it has a hexameric 'stack' arrangement with a $\mathrm{Ti}_{6} \mathrm{O}_{6}$ core (Fig. 1A). Each of the chemically-equivalent $\mathrm{Ti}(\mathrm{IV})$ centre has a six-coordinate, octahedral geometry, being bonded to three $\mu_{3}-\mathrm{O}$ oxo-atoms within the core, three $\mathrm{O}$ atoms from two TA ligands and one isopropoxide-O atom. The peripheral "thiophene tentacles" are aligned in opposite directions

Crystals of POT-1 are probably stable in air and soluble in various organic solvents like toluene, tetrahydrofuran, chloroform and dichloromethane (DCM). Room-temperature ${ }^{1} \mathrm{H}$ NMR spectrum of POT-1 in $\mathrm{CDCl}_{3}$ shows one doublet corresponding to the methyl- $\mathrm{H}$ at 1.2-1.3 ppm and one septet associated to $-\mathrm{CH}$ near 4.8-5.0 ppm which represent the 'PrO ligands (Fig. S1). The three signals at 7.20, 7.11 , and $6.98 \mathrm{ppm}$ with the relative intensity is near $1: 1: 1$ as well as the singlet at $3.55 \mathrm{ppm}$ are belong to the characteristic peaks of thiophene-3-acetic acid. The peak area ratios in ${ }^{1} \mathrm{H}$ NMR indicate that the ratio of the TA to PrO ligands in POT-1 is 1:1 (Fig. S1). Interestingly, the NMR spectrum for POT-1 is not obviously changed 
with concentration, which suggests that the structure remains the same in $\mathrm{CDCl}_{3}$.

As shown in Fig. S3, The +ve ion electrospray mass spectrum shows a signal at $\mathrm{m} / \mathrm{z}=1586.87$ for $[\mathrm{M}+\mathrm{H}]^{+}$(calc. 1585.92). The bulk purity of crystalline POT-1 is confirmed by the powder X-ray diffraction ( $p X R D)$ spectrum which is identical to the pattern derived from its sXRD data (Fig. S2). Thermogravimetric (TGA) and differential thermal analysis (DTA) show that POT-1 is not thermally decomposed at temperatures lower than $150^{\circ} \mathrm{C}$ (Fig. S4). Comparable with reported POT cages, the band gap determined from the solutionstate UV visible spectrum of POT-1 is ca. $3.79 \mathrm{eV}$ (Fig. S5). ${ }^{28}$

POT-1 is the first structurally determined POT cage in which the assembly is achieved exclusively by incorporation of polymerizable TA ligand into a $\mathrm{Ti}_{\mathrm{x}} \mathrm{O}_{\mathrm{y}}$ core.

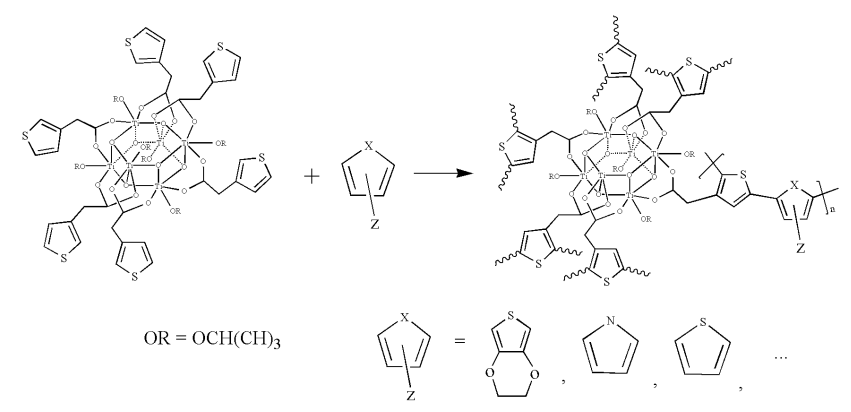

Scheme 1 copolymerization strategy used to obtain conjugated hybrid materials from POT-1.

Cyclic voltammetry (CV) curves of POT-1 in a DCM solution of 0.1 $M$ tetrabutylammonium hexafluorophosphate (TBAH) exhibit an irreversible multistage oxidation process with initial oxidation potential at $1.05 \mathrm{~V}$, very close to that of EDOT (Fig. S7). The similarity of the initial oxidation potentials was propitious for the controllable formation of the copolymers. ${ }^{29-30}$. Subsequently, a series of conjugated hybrid films Poly-(EDOT-POT)s was produced by electrochemical copolymerization of POT-1 with EDOT indium-doped tin oxide (ITO) glass substrates by a potentiostatic method (See ESI+) (Scheme 1).

As shown in Fig. 2, a series of Poly-(EDOT-POT)s with various morphologies were prepared through potentiostatic copolymerization of POT-1 and EDOT with a 1:1 molar ratio at different anodic potentials. It is noteworthy that a $3 \mathrm{D}$ nanoporous film named Poly-(EDOT-POT)-1 was obtained at 1.7V. To the best of our knowledge, this phenomenon was observed for the first time, and may be due to the multiple polymerizable sites and multistage oxidation processes of POT-1 that can lead to various polymer networks under different electrochemical conditions. As shown in Fig. S8, the morphology of Poly-(EDOT-POT)s films can also be altered significantly by adjusting the proportion of POT-1 and EDOT COmonomers.

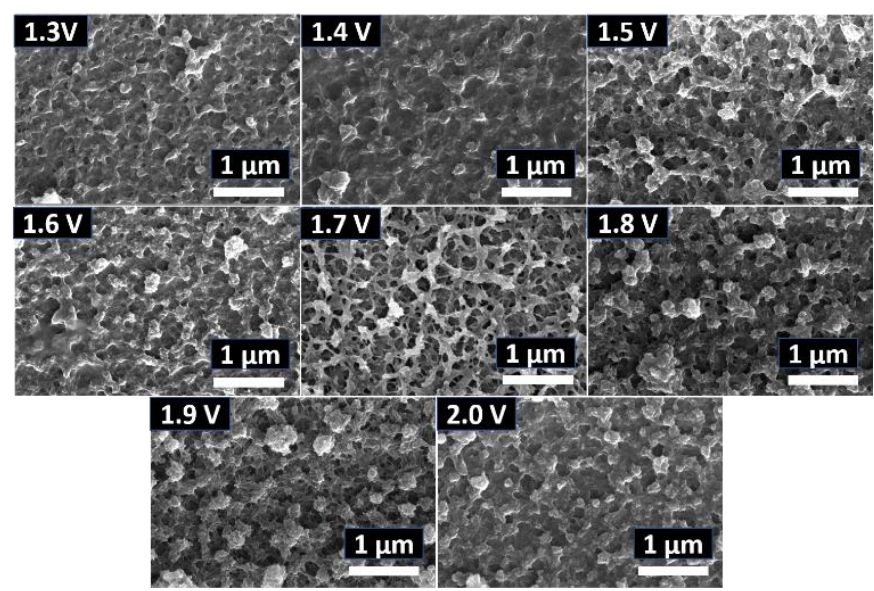

Fig. 2 SEM images of Poly-(EDOT-POT)s films on ITO electrodes through potentiostatic copolymerization of POT-1 and EDOT ( $1: 1$ molar ratio) on ITO at $1.3 \mathrm{~V}, 1.4 \mathrm{~V}, 1.5 \mathrm{~V}, 1.6 \mathrm{~V}$, $1.7 \mathrm{~V}, 1.8 \mathrm{~V}, 1.9 \mathrm{~V}$ and $2.0 \mathrm{~V}$ respectively.

Energy dispersive spectroscopy (EDS) suggests that Poly-(EDOTPOT)-1 contains $2.05 \%$ atom $\% \mathrm{Ti}$ atoms (Fig. S14, Table S3), and element mapping indicates that $\mathrm{Ti}$ is disperse homogeneously in the matrix (Fig. 3). Poly-(EDOT-POT)-1 is a stable film where the dispersion of Ti in Poly-(EDOT-POT)-1 was not changed after soaked in DCM even during 2 weeks (Fig. S18).

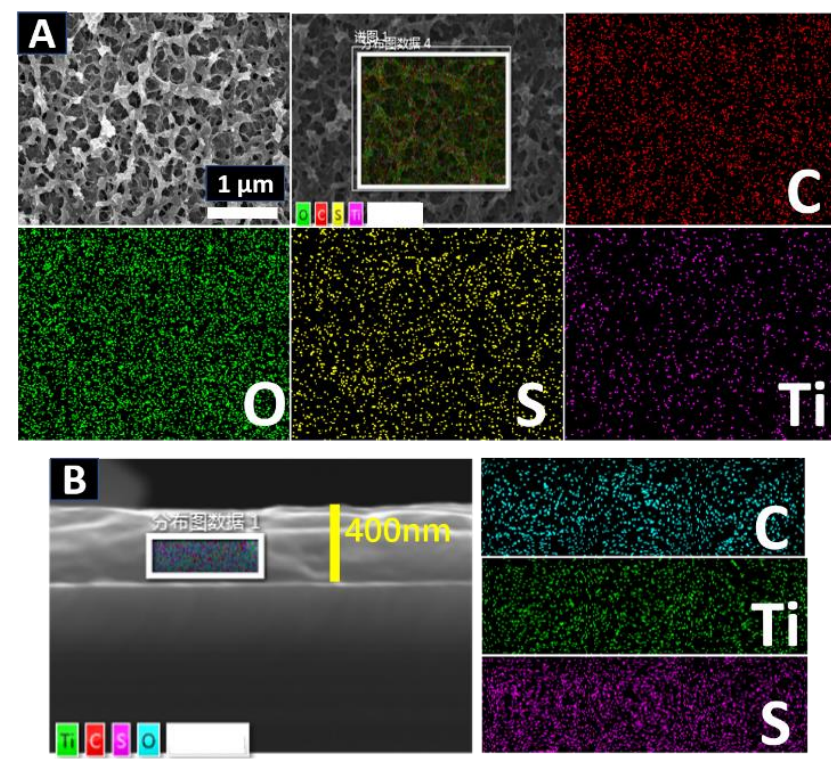

Fig. 3 SEM and element mapping of plane (A) and section (B) of the Poly-(EDOTPOT)-1 film.

CV curves of Poly-(EDOT-POT)-1 and PEDOT films on a glassy carbon electrode were tested in a three-electrode system with $\mathrm{Ag} / \mathrm{AgCl}$ as reference electrode. As shown in Fig. S19, PEDOT film exhibits a redox pair $\left(E_{p c}=-0.59 \mathrm{~V}, E_{p a}=0.09 \mathrm{~V}\right)$ in the potential range from -0.8 to $1.5 \mathrm{~V}$, while there is only one significant reduction peak around $0.20 \mathrm{~V}$ for the film of Poly-(EDOT-POT)-1 at scan rate of 10 $\mathrm{mV} / \mathrm{s}$. 

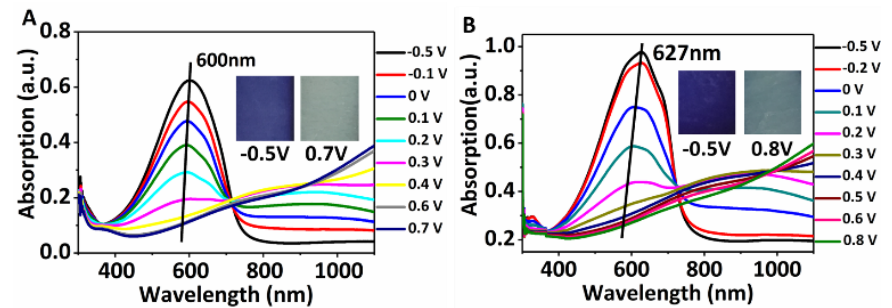

Fig. 4 UV-vis spectra of (A) Poly-(EDOT-POT)-1 and (B) PEDOT at applied voltages between $-0.8 \mathrm{~V}$ and $1.2 \mathrm{~V}$ in $0.1 \mathrm{M} \mathrm{TBAH} / \mathrm{DCM}$ solution (inset are the photographs of the corresponding polymer films on ITO glass).

Visible and NIR transmission spectra of Poly-(EDOT-POT)-1 and PEDOT on ITO at different potentials are shown in Fig. 4. Like PEDOT, Poly-(EDOT-POT)-1 is a cathodically-colouring material with the colour changed from dark blue (coloured state) at $-0.5 \mathrm{~V}$ to light-blue (bleached state) at $0.7 \mathrm{~V}$. In the coloured state, the visible absorption band of Poly-(EDOT-POT)-1 $(600 \mathrm{~nm})$ is blue shifted compare with that of PEDOT (627 nm), which may be due to the attachment of POT-1 to the conjugated backbone. As shown in Fig. 5, Poly-(EDOTPOT)-1 exhibits improved electrochromic properties with larger optical contrast $(53.0 \%)$ and shorter coloring time (1.36 s) compare with that of PEDOT (50.7\% optical contrast, 1.59s coloring time), which may be due to the nanoporous structure of Poly-(EDOT-POT)1.
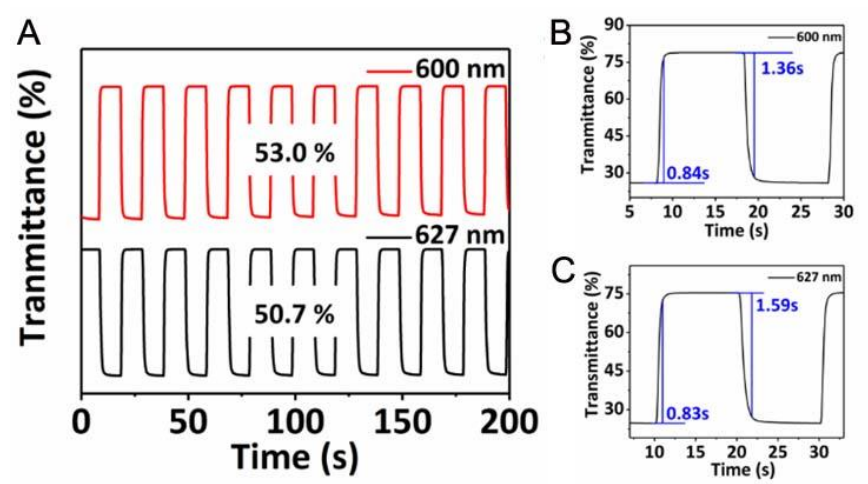

Fig. 5 Optical contrast of the Poly-(EDOT-POT)-1 (red curve) polymer films monitored between $-0.5 \mathrm{~V}$ and $0.7 \mathrm{~V}$ and the PEDOT (black curve) films monitored between $-0.5 \mathrm{~V}$ and $0.8 \mathrm{~V}$ in $0.1 \mathrm{M} \mathrm{TBAH} / \mathrm{DCM}$ solution with a residence of $10 \mathrm{~s}(\mathrm{~A})$; Electrochromic switching response of Poly-(EDOT-POT)-1 (B) and PEDOT (C).

As an electrode material for supercapacitor Poly-(EDOT-POT)-1 was further tested in a three-electrode system using $0.1 \mathrm{M}$ $\mathrm{LiClO}_{4} / \mathrm{ACN}$ as the electrolyte (ESI+). Nyquist plots of Poly-(EDOTPOT)-1 and PEDOT are shown in Fig. S20. It can be seen that the internal resistance of Poly-(EDOT-POT)-1 is smaller than that of PEDOT, which suggests that the Poly-(EDOT-POT)-1 electrode has better conductive properties ${ }^{31}$ and consequent electrochemical properties.

CV curves of Poly-(EDOT-POT)-1 and PEDOT both exhibit a quasirectangular shape at sweep rates from 10 to $300 \mathrm{mV} / \mathrm{s}$, but the specific capacitance of Poly-(EDOT-POT)-1 is larger than that of PEDOT especially at higher scanning rate (Fig.6A, 6B); chargedischarge curves at current densities between $1 \mathrm{~A} / \mathrm{g}$ and $5 \mathrm{~A} / \mathrm{g}$ display regular-triangular shapes and no obvious voltage drop can be observed at the beginning of the discharge process for both the Poly(EDOT-POT)-1 and PEDOT electrodes indicating ideal capacitor behaviour (Fig.6C, 6D). It is noteworthy that the specific capacitance of Poly-(EDOT-POT)-1 is $102.5 \mathrm{~F} / \mathrm{g}$ at a current density of $1 \mathrm{~A} / \mathrm{g}$ much higher than that of bare PEDOT $(75.8 \mathrm{~F} / \mathrm{g})$. With the increase of current densities to $5 \mathrm{~A} / \mathrm{g}$, the specific capacitance of Poly-(EDOTPOT)-1 decreases to $94.1 \mathrm{~F} / \mathrm{g}$, 34\% higher than that of PEDOT which is 70.3 F/g (Fig. 6E). As shown in Fig. 6F, Poly-(EDOT-POT)-1 delivered a higher energy density of $14.2 \mathrm{Wh} / \mathrm{kg}$ at power density of $500 \mathrm{~W} / \mathrm{kg}$ and a higher power density of $2500 \mathrm{~W} / \mathrm{kg}$ at energy density of 13.1 Wh/kg compare with that of PEDOT. These results indicate that Poly(EDOT-POT)-1 is a promising electrode material suitable for fast ion transport. ${ }^{32}$
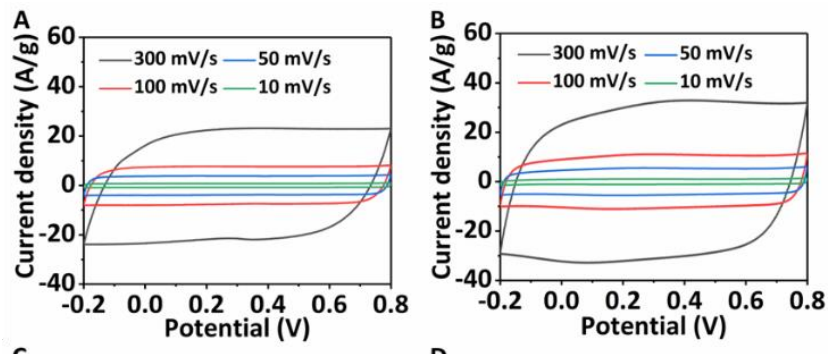

C
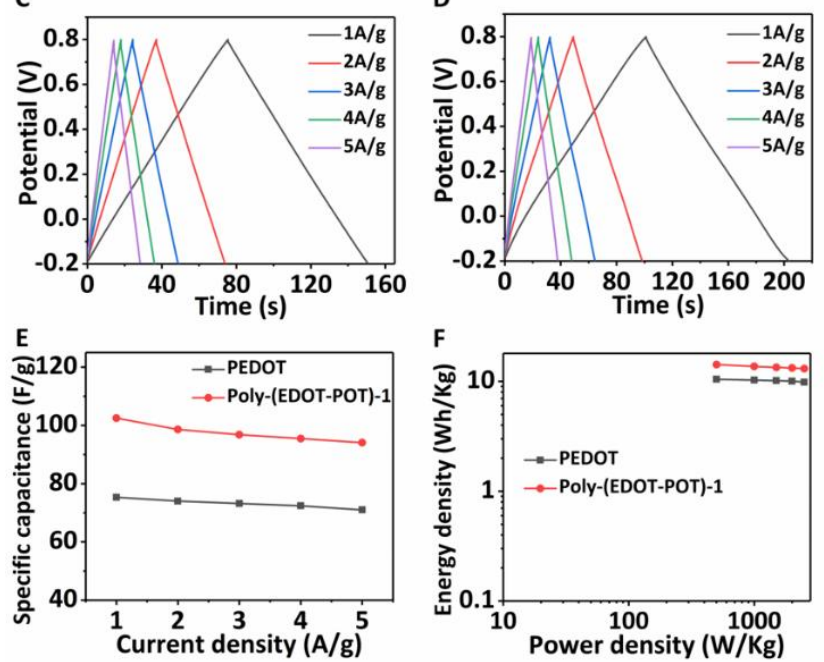

Fig. $6 \mathrm{CV}$ curves of PEDOT (A) and Poly-(EDOT-POT)-1 (B); galvanostatic charge/discharge curves of PEDOT (C) and Poly-(EDOT-POT)-1 (D); specific capacitance calculated from discharge curves of PEDOT and Poly-(EDOT-POT)-1 (E); Ragone plots of PEDOT and Poly-(EDOT-POT)-1 (F).

\section{Conclusions}

In summary, POT-1 is the first structurally determined POT cage in which the assembly is achieved exclusively by incorporation of polymerizable TA ligand into a $\mathrm{Ti}_{\mathrm{x}} \mathrm{O}_{\mathrm{y}}$ core. A series of conjugated hybrid films Poly-(EDOT-POT)s has been synthesized employing the POT-1 as a nanobuilding block. 3D nanoporous film Poly-(EDOTPOT)-1 is a promising electrode material suitable for fast ion transport and exhibit improved electrochromic properties and 35\% higher capacitance (102.5 F/g) compared with that of PEDOT (75.8 $\mathrm{F} / \mathrm{g}$ ) at a current density of $1 \mathrm{~A} / \mathrm{g}$.

\section{Conflicts of interest}

There are no conflicts to declare.

\section{Acknowledgements}


We sincerely thank National Natural Science Foundation of China (NSFC, No. 21501148).

\section{Notes and references}

1 L. Lin, H. Wang and P. Xu, Chem. Eng. J., 2017, 310, 389398.

2 N. Singh, Z. Salam, A. Subasri, N. Sivasankar and A. Subramania, Sol. Energy Mater. Sol. Cells, 2018, 179, 417426.

3 D. Zheng, Y. Xin, D. Ma, X. Wang, J. Wu and M. Gao, Catal. Sci. Technol, 2016, 6, 1892-1902.

4 B. Li, B. Xi, Z. Feng, Y. Lin, J. Liu, J. Feng, Y. Qian and S. Xiong, Adv. Mater., 2018, 30, 1705788.

5 J. Wang, W. Liu, H. Li, H. Wang, Z. Wang, W. Zhou and H. Liu, Chem. Eng. J., 2013, 228, 272-280.

6 J. Liu, Z. Cai, Y. Lv, Y. Zhang, C. Su, M. Ouyang, C. Zhang and D. S. Wright, J. Mater. Chem. A, 2015, 3, 1837-1840.

7 J. Ma, W. Liu, X. Liang, B. Quan, Y. Cheng, G. Ji and W. Meng, J. Alloys Compd., 2017, 728, 138-144.

8 T. D. Savić, Z. V. Šaponjić, M. I. Čomor, J. M. Nedeljković, M. D. Dramićanin, M. G. Nikolić, D. Ž. Veljković, S. D. Zarić and I. A. Janković, Nanoscale, 2013, 5, 7601-7612.

9 M.-B. Alexandra, L.-C. María, F.-G. Marta, K. Anna, F. Manuel and F.-G. Marcos, Int. J. Mol. Sci., 2013, 14, 92499266.

10 (a) M. Ihalainen, T. Lind, T. Torvela, K. E. J. Lehtinen and J. Jokiniemi, Aerosol Sci. Technol, 2012, 46, 990-1001; (b) B. Luo, Y. Deng, Y. Wang, Z. Zhang and M. Tan, J. Alloys Compounds, 2012, 517, 192-197; (c) X. Hua, F. L. Bei, and X. Wang, J. Appl. Polym. Sci., 2009, 112, 3582-3588.

11 C. Zhao, Y.-Zi. Han, S. Dai, X. Chen, J. Yan, W. Zhang, H. Su, S. Lin, Z. Tang, B. K. Teo and N. Zheng, Angew. Chem., Int. Ed., 2017, 56, $16252-16256$.

12 H. Assi, G. Mouchaham, N. Steunou, T. Devic and C. Serre, Chem. Soc. Rev., 2017, 46, 3431-3452.

13 G. Zhang, C. Liu, D.-L. Long, L. Cronin, C.-H. Tung and Y. Wang, J. Am. Chem. Soc., 2016, 138, 11097-11100.

14 P. I. Molina, K. Kozma, M. Santala, C. Falaise and M. Nyman, Angew. Chem., Int. Ed., 2017, 56, 16277 -16281.

15 Y. Lv, Z. Cai, D. Yan, C. Su, W. Li, W, Chen, Z. Ren, Y. Wei, O. Mi, C. Zhang and D. S. Wright, RSC Adv., 2016, 6, 57-60.

16 Y. Lv, W. Du, Y. Ren, Z. Cai, K. Yu, C. Zhang, Z. Chen and D. S. Wright, Inorg. Chem. Front., 2016, 3, 1119-1123.

17 Y. Fan, H.-M. Li, R.-H. Duan, H.-T. Lu, J.-T. Cao, G.-D. Zou and Q.-S. Jing, Inorg. Chem., 2017, 56, 12775-12782.

18 P. Ji, Y. Song, T. Drake, S. S. Veroneau, Z. Lin, X. Pan and W. Lin, J. Am. Chem. Soc., 2018, 140, 433-440.

19 G. Zhang, W. Li, C. Liu, J. Jia, C.-H. Tung and Y. Wang, J. Am. Chem. Soc., 2018, 140, 66-69.

20 F. G. Svensson, G. A. Seisenbaeva and Va. G. Kessler, Eur. J. Inorg. Chem., 2017, 35, 4117-4122.
21 W. H. Fang, L. Zhang and J. Zhang, Chem. Commun., 2017, 53, 3949-3951.

22 L. Rozes and C. Sanchez, Chem. Soc. Rev., 2011, 40, 10061030.

23 C. Sanchez, C. Boissiere, S. Cassaignon, C. Chaneac, O. Durupthy, M. Faustini, D. Grosso, C. Laberty-Robert, L. Nicole, D. Portehault, F. Ribot, L. Rozes and C. Sassoye, Chem. Mater., 2014, 26, 221-238.

24 G. L. Drisko and C. Sanchez, Eur. J. Inorg. Chem., 2012, 32, 5097-5105.

25 L. Rozes, G. Fornasieri, S. Trabelsi, C. Creton, N. E. Zafeiropoulos, M. Stamm and C. Sanchez, Prog. Solid State Chem., 2005, 33, 127-135.

26 S. Trabelsi, A. Janke, R. Hässler, N. E. Zafeiropoulos, G. Fornasieri, S. Bocchini, L. Rozes, M. Stamm, J.-F. Gérard and C. Sanchez, Macromolecule, 2005, 38, 6068-6078.

27 F. Périneau, S. Pensec, C. Sassoye, F. Ribot, L. Lokeren, R. Willem, L. Bouteiller, C. Sanchez and L. Rozes, J. Mater. Chem., 2011, 21, 4470-4475.

28 (a) Y. Chen, J. Sokolow, E. Trzop, Y.-S. Chen and P. Coppens, J. Chin. Chem. Soc., 2013, 60, 887; (b) Y. Lv, J. Cheng,P. D. Matthews, J. P. Holgado, J. Willkomm, M. Leskes, A. Steiner, D. Fenske, T. C. King, P. T. Wood, L. Gan, R. M. Lambert and D. S. Wright, Dalton Trans., 2014, 43, 8679-8689; (c) Y. Chen, E. Trzop, A. Makal, Y.-S. Chen and P. Coppens, Dalton Trans., 2014, 43, 3839.

29 C. L. Gaupp and J. R. Reynolds, Macromolecules, 2003, 36, 6305-6315

30 (a) C. Zhang, C. Hua, G. Wang, M. Ouyang and C. Ma, Electrochim. Acta, 2010, 55, 4103-4111. (b) Yaokang L, Liu Y, Yun P, et al. Preparation,Characterisation and Electrochromic Properties of Copolymer Films Based on 3,4Ethylenedioxythiophene and Pyrrole-3-Carboxylic Acid · [J]. Chemical Journal of Chinese Universities, 2017.

31 X. Xu, W. Shi, P. Li, S. Ye, C. Ye, H. Ye, T. Lu, A. Zheng, J. Zhu, L. Xu, M. Zhong and X. Cao, Chem. Mater., 2017, 29, 6058-5065.

32 (a) Z. Xu, J. Wang, Z. Hu, R. Geng and L. Gan, Electrochim. Acta, 2017, 231, 601-608. (b) W. Du, Y. Lv, Z. Cai, C. Zhang, Acta Phys. Chim. Sin. 33 (9) (2017) 1828-1837. 